\title{
GRAMÁTICA EM PROVAS DE CONCURSOS PÚBLICOS: QUO VADIS?
}

\author{
Rosane Reis Oliveira (UERJ) \\ Pablo Jamilk Flores (UNIOESTE) \\ Denis Rogério Romagnoli (UFPel)
}

Resumo: Discutimos, no presente texto, sérios problemas que envolvem a cobrança de conceitos gramaticais em provas de concursos púbicos. A prova de Língua Portuguesa é obrigatória nos exames de seleção de candidatos a cargos no Serviço Público há muitos anos, sem que a qualidade do que se exige dos candidatos acerca do conhecimento vernacular tenha sido tema de discussão. Há problemas com questões mal formuladas, teorias e nomenclaturas diversas, falta de consenso a respeito daquilo que deva ser cobrado, apesar de todos concordarem que o padrão culto, formal, da língua deva ser exigido. Por conta desses tantos problemas, apresentamos, neste artigo, algumas das divergências conceituais, a fim de iniciar debate a respeito de irrelevâncias, inconsistências e nomenclaturas, operadas nas provas desses concursos. Cotejamos os pressupostos nomenclaturais da Nomenclatura Gramatical Brasileira (NGB) com os pesquisadores críticos dessa proposta - Nascentes (1959), Neves (2002) e Henriques (2009) - com o fito de trazer à baila as complicações provenientes da prática de se exigir memorização de nomenclatura e aplicação de regras que - em diversas situações - sequer constam dos editais. Ainda nesta oportunidade, apresentamos algumas questões que demonstram a arbitrariedade de cobrança de algumas bancas examinadoras de concursos. O objetivo deste artigo é iniciar um alerta de que há necessidade de exigir mudança de diretriz nos concursos públicos, por não estarem selecionando com precisão os candidatos melhores em competência linguística para exercerem os cargos a que se destinam.

Palavras-chave: Gramática; Concurso Público; Nomenclaturas.

Abstract: We discuss, in this text, serious problems that involve the collection of grammatical concepts in public contest. The Portuguese language test is mandatory in the examinations of candidates for positions in the Public Service for many years, without the quality of what is required of the candidates about vernacular knowledge has 
been the subject of discussion. There are problems with ill-formulated questions, diverse theories and nomenclatures, lack of consensus about what should be charged, although everyone agrees that the formal, formal pattern of language should be required. Because of these many problems, we present in this article some of the conceptual differences, in order to initiate debate about irrelevances, inconsistencies and nomenclatures, operated in the tests of these contests. We compare the nomenclature assumptions of the Brazilian Grammatical Nomenclature (NGB) with the critical researchers of this proposal - Nascentes (1959), Neves (2002) and Henriques (2009) - with the aim of bringing to light the complications arising from the practice of requiring memorization of nomenclature and application of rules that - in several situations - do not even appear in the edicts. Still on this occasion, we present some questions that demonstrate the arbitrariness of collection of some examining boards of contests. The purpose of this article is to initiate an alert that there is a need to require a change of directive in public tenders because they are not accurately selecting the best candidates in linguistic competence to perform the duties for which they are intended. Keywords: Grammar; Public tender; Nomenclatures.

\section{PREÂMBULO DO PROBLEMA}

Quando um indivíduo - resgatado de uma rotina exaustiva de trabalho e ciente de uma gama de frustrações profissionais - resolve prestar um concurso público (na intenção de conseguir uma remuneração relativamente maior e uma estabilidade que não conheceria na iniciativa privada), depara-se com diversos editais distintos, os quais exigem alguns conhecimentos ditos "básicos" e outros nomeados como "específicos". Usualmente, entre aquilo que se indica como básico nesses editais, há o conhecimento do funcionamento e dos recursos da Língua Portuguesa, 
de Atualidades, de Raciocínio lógico-matemático (que mais lembra a Semântica Formal) e de algumas noções relativas ao Direito. Em uma análise breve de um par de provas aplicadas nesses processos de seleção, fica evidente que é possível nomear esses conhecimentos com qualquer outro adjetivo, menos como "básicos".

Além do problema de aprofundamento com que se cobram os tópicos, nota-se pouca ou nenhuma uniformidade nos conteúdos arrolados nos editais das bancas examinadoras que vencem as licitações para a realização dos concursos públicos, fato que dificulta enormemente a escolha de um direcionamento teórico na preparação dos candidatos ou mesmo de uma metodologia de trabalho docente para os que atuam nessa área. $\mathrm{O}$ resultado disso é uma miríade de recursos contra questões da prova de Língua Portuguesa, cujos examinadores se digladiam sob perspectivas teóricas diferentes, sem uma ferramenta hermenêutica que permita julgar de maneira isonômica os posicionamentos de pesquisadores, autores, avaliadores e candidatos.

Sendo assim, o presente texto aborda alguns dos pontos mais controversos de exames mais recentes, a fim de que seja possível lançar um olhar teórico a respeito do problema. Espera-se, com isso, abrir um debate com vista 
a buscar uma metodologia avaliativa menos doxológica e mais epistemológica, e que também se possam trazer mais garantias tanto para os que avaliam quanto para os que são avaliados - estes investem tempo, dinheiro, aspirações e expectativas em sua preparação.

\section{DOS PROBLEMATIZADORES}

O problema parece ter início na descontinuidade bibliográfica que se adota para a formulação das questões empregadas nos certames. Cada banca adota uma direção avaliativa, privilegiando alguns conhecimentos em detrimento de outros. A escolha da abordagem e a nomenclatura dos recursos e fatos da língua dependem da(s) teoria(s) que os examinadores adotam como suporte da prática pedagógica. Isso exige que o profissional que há de trabalhar na preparação dos candidatos, além de conhecer muito bem o conteúdo que pode ser cobrado nas provas de diferentes bancas, conheça particularmente as perspectivas adotadas por cada uma, como se houvesse um tipo de "entendimento particular" da gramática normativa e de tantas outras vertentes teóricas com que se analisam os recursos linguísticos (como a análise do discurso, a linguística textual, a pragmática, a semântica e outros estudos), a integrar o domínio dos professores e o cabedal dos candidatos. 
Como se tudo isso não bastasse, as diferentes bancas não variam apenas a tipologia de suas questões e as teorias adotadas, mas também a escolha dos conteúdos da matéria, divergindo, em alguns casos (conforme já dissemos), quanto à corrente teórica ou mesmo quanto à Nomenclatura Gramatical Brasileira (NGB). É comum que se encontrem divergências em relação à bibliografia informada como subsidiária das questões ou como referência de estudo para os candidatos. Ademais, quase nunca a bibliografia se encontra explicitada nos editais, o que dificulta ainda mais a preparação do candidato e o embasamento aos futuros recursos que contestem a formulação teórica cobrada.

Sabemos, também, que as turmas preparatórias para concursos de provimento de vagas no Serviço Público do tipo em análise atendem a uma clientela de candidatos que, em sua maioria, estão afastados dos estudos desde o término do Ensino Médio. Esse despreparo se materializa em dúvidas sobre questões fundamentais da normatização da Língua Portuguesa, cujo conhecimento apresenta falhas e lacunas conceituais, refletindo no conhecimento das estruturas dessa língua, e afastando os alunos dos conteúdos que efetivamente contribuem para a prática linguística mais próxima da norma padrão, cobrada nos concursos públicos. 
Os modismos teóricos atropelam os que vão prestar concursos.

Outro empecilho é a escassez de material didático de qualidade, que contenha não somente o apoio gramatical pertinente ao conteúdo e modo de cobrança dessas provas, mas principalmente uma leitura crítica, que alerte os candidatos para as tendências de cada concurso na abordagem dos conteúdos. Somente nos últimos anos, editoras especializadas na área passaram a publicar material específico com vista a minimizar essa deficiência de ensino e de aprendizagem da Língua Portuguesa em seu uso formal, conforme o que se espera do candidato nos concursos públicos. A Gramática para Concursos Públicos, de Fernando Pestana ${ }^{1}$, é um expoente nesse mercado, já que aborda a maior parte dos problemas encontrados nessas provas, sendo atualizada pelo autor a cada dois anos.

Como se fossem poucos os problemas já apontados, também a prática linguística dos candidatos (quase sempre afastada do uso culto) interfere na identificação da resposta correta para o problema contido na questão de prova, pelo simples fato de não haver coincidência entre a experiência linguística do falante e as estruturas eleitas pela banca para

1 PESTANA, Fernando. A gramática para concursos públicos. Rio de Janeiro: Editora Campus Concursos, 2013. 
avaliação do domínio do vernáculo. A Língua Portuguesa cobrada nas questões de concurso não é a mesma língua utilizada pelos candidatos no falar cotidiano e hoje privilegiada no ensino por certa corrente teórica que se pauta no preconceito relativo à variação linguística. A língua padrão (ou culta), muitas vezes desprestigiada e estigmatizada, é a que os candidatos encontram para a sala de aula dos cursos preparatórios, e isso gera, nos aprendizes, de um modo geral, pré-conceitos como o de não saberem a língua nacional e o de julgarem-na muito difícil. A atitude diversificada das bancas acaba exigindo do candidato não apenas a habilidade de identificar respostas pautadas em normas gramaticais alheias a sua prática, mas sobretudo a capacidade de raciocinar sobre a língua e seus usos, levando em conta a relação entre o gênero textual e a variedade linguística privilegiada. É claro que, nos concursos, a língua funcional que é referência de domínio verbal exigida é a padrão, ou culta. Entretanto, a competência ampliada para a linguística textual, a análise do discurso e outros ramos dos estudos da língua se tornam uma exigência para o sucesso nesses certames. O candidato deve, pois, ser capaz de discutir um enunciado, aventando-lhe (posto, pressuposto, inferências, ilações etc.) possibilidades estruturais-argumentativas, saber as diferentes teorias estudadas nas faculdades de Letras 
e publicadas em revistas científicas, por meio de artigos redigidos pelos mesmos doutores que elaboram as provas, para enfrentar as sutilezas das questões que, por sua vez, representam a subjetividade das bancas. Ou seja, impossível, improvável e inadmissível, se considerarmos a prática, em vez das tão distantes teorias!

Com base nos problemas de inconsistência bibliográfica apontados anteriormente, entramos a discutir com amigos professores que trabalham no segmento de concursos públicos e se sentem indignados com diversos tipos de arbitrariedades nas provas de Língua Portuguesa que servem de avaliação para o provimento de vagas em cargos públicos, tanto em nível médio, quanto em nível superior, algo que, pelas expectativas geradas nos candidatos no tocante às mudanças que uma provável nomeação acarretaria em suas vidas, e também pela responsabilidade de se tornar um futuro servidor público, deveria exigir um pouco mais de atenção por parte tanto de quem avalia quanto de quem contrata os avaliadores. De tanto conversarmos isoladamente em redes sociais e aplicativos de conversa instantânea, um dos professores, Fernando Pestana, decidiu criar um grupo no aplicativo usado em plataforma digital mobile, extensivo ao uso em computadores, cujo foco inicialmente era a discussão 
de questões de Língua Portuguesa com um gabarito inconsistente ou nebuloso. Essa agremiação de professores, pesquisadores e amantes do idioma pôs-se a refletir sobre alguns problemas relativos à ausência de uniformização na cobrança, e alguns conteúdos em provas de concursos públicos. Aos poucos esse grupo foi crescendo e fomos convidando professores de todo o Brasil. Atualmente o grupo conta com a presença de mais de 40 participantes e se chama "Grupo do Bigode". Os autores deste artigo são participantes ativos desse grupo, donde retiramos parte de nosso corpus para as análises apresentadas a seguir.

Posteriormente, assim que houve maior número de participantes, propôs-se a criação de um documento (um dossiê) para reunir os casos mais graves de inconsistência conceitual que foram registrados em algumas provas analisadas. Esse documento - ainda em fase de construção abarca uma quantidade expressiva de pontos inconclusivos, os quais representariam um desafio até ao mais preparado dos candidatos.

\section{ALGUMAS DISCUSSÕES PERTINENTES}

Com o objetivo de exemplificar alguns dos problemas apontados anteriormente, trouxemos à baila questões já discutidas no Grupo do Bigode. 
Registrem-se as seguintes questões:

1 - ${ }^{2} F U N C A B$ - Faceli - Técnico

Administrativo - 2015

- São acentuadas por diferentes razões:

(A) crônicas, páginas

(B) clichês, pé

(C) família, irreconhecível (gabarito)

(D) lírico, rápida

(E) inútil, irrecuperável

2 - FUNCAB - CRF/RO - Auxiliar de Serviços Gerais - 2015

- Recebem acento pela mesma razão:

(A) ódio, silêncio. (gabarito)

(B) primário, paletó.

(C) atraída, óculos.

(D) cólera, contraídos.

(E) até, vê.

É possível identificar, no que se pontua acima, a ausência de critério avaliativo a respeito do assunto cujo conhecimento é exigido, qual seja acentuação gráfica. Espera-se, portanto, que o candidato seja capaz de identificar princípios que regem as regras de acentuação das palavras em Língua Portuguesa. É importante observar que se trata de questões da mesma banca examinadora, do mesmo ano, diferindo apenas o concurso. Nota-se que, na comparação entre as duas questões, há uma discrepância em relação à intepretação dessas mesmas regras. Na questão 1 , os casos são de (a) proparoxítonas; (b) oxítona terminada em 'e' e monossílabo

2 Extraído de Fundação Professor Carlos Alberto Bittencourt. O levantamento se deve a Fernando Pestana. 
tônico terminado em ' $\mathrm{e}$ ' (um verdadeiro "Triângulo das Bermudas", ainda nos mais respeitados materiais teóricos); (c) paroxítona terminada em ditongo, paroxítona terminada em 'l'; (d) proparoxítonas; (e) paroxítonas terminadas em 'l'. Na questão 2, os casos são de (a) paroxítonas terminadas em ditongo; (b) paroxítona terminada em ditongo, oxítona terminada em 'o'; (c) hiato tônico com a letra 'i', proparoxítona; (d) proparoxítona, hiato tônico com a letra 'i'; (e) oxítona terminada em 'e', monossílabo tônico terminado em 'e'.

Por meio dessa descrição, é plausível afirmar que os examinadores os quais propuseram os dois questionamentos não se preocuparam com uniformidade em relação à concepção das regras relativas à acentuação: inicialmente, não se determina se há uma distinção entre regras das paroxítonas por causa das terminações (ditongo ou consoantes $R, X, L, P S)$. Além disso, os examinadores consideram que uma palavra monossílaba se acentua com base na mesma regra das palavras oxítonas. A razão para esse posicionamento repousa no Decreto 6.583/2008 - do Novo Acordo Ortográfico da Língua Portuguesa - que ainda não separa as oxítonas das monossílabas terminadas em $A(s), E(s), O(s)$ na justificativa do acento. Como o candidato poderia ter acesso a esse conhecimento, tomando por base 
materiais didáticos que promovem a separação dessas regras? Como arbitrar sobre esses princípios de acentuação em um certame de seleção para cargo público, sem indicar sob qual perspectiva teórica se constrói a avaliação? Essas são questões sérias e merecem um tratamento específico por parte dos pesquisadores.

Tamanha é a incoerência da banca examinadora, que, no mesmo ano, mas em concursos diferentes, a examinadora cobrou acentuação gráfica, divergindo dela própria, quando aceitou as palavras da letra $B$, questão 1 , clichês e pé, como acentuadas pela mesma razão. Mas, na questão 2, como podemos ver, classifica as palavras da letra E, até e vê, como acentuadas por razões diferentes. O candidato e o professor ficam sem saber qual critério adotar na preparação para concursos em que a banca FUNCAB é eleita como organizadora. Afinal, as oxítonas terminadas em $A(s), E(s)$ e $\mathrm{O}(\mathrm{s})$ e as monossílabas tônicas com as mesmas terminações fazem ou não parte do mesmo grupo de palavras na justificativa da acentuação?

\section{IRRELEVÂNCIA E INCONSISTÊNCIAS}

Queremos também ressaltar aqui a irrelevância de alguns tópicos cobrados nesses certames, bem como algumas das inconsistências encontradas nas análises que vimos 
realizando ao longo dos anos trabalhando com turmas preparatórias. Alguns de nós, professores de "cursinho" (como somos chamados de forma pejorativa por muitos de nossos pares), somos pós-graduados e até docentes de universidades de renome. Outros tantos se ocupam também de projetos de pesquisa, de participação em congressos e demais eventos acadêmicos, de produção de artigos científicos, de livros (produções nacionais e internacionais), ou seja, somos Mestres e Doutores em Letras, e também dignos preparadores de pessoas que intentam mudar suas vidas, ingressando no serviço público e merecemos todo respeito. Depois dessa breve introdução, pomo-nos a relatar algumas das inconsistências e irrelevâncias dos tópicos cobrados nas provas de Língua Portuguesa.

Uma das maiores reflexões com que damos início a este trecho do nosso trabalho é sobre o que se deve cobrar de um candidato a uma vaga no serviço público. Essas não são provas para especialistas em Letras e Linguística, mas para falantes comuns, que se pretendem avançados, de quem se espera uma proficiência razoável de língua. O que se quer avaliar nessas provas? Será que estudos científicos da análise do discurso, da pragmática, da nova abordagem que trata de modalizações, análise de aspecto verbal, cálculo inferencial (para mencionar apenas alguns) deveriam ser componentes 
dos programas dos quais resultam essas provas? Pensamos haver um equívoco sobre quais conteúdos abordar, o que acaba por prejudicar os candidatos, que se veem perdidos em meio a tantas teorias novas e científicas que jamais deveriam compor quaisquer exames cuja finalidade não seja a escolha de candidatos a cargos de professores de português. Parece que os itens ${ }^{3}$ dessas avaliações refletem o posicionamento dos professores-pesquisadores que elaboram as provas, ou seja, exigem um conhecimento acadêmico que está muito distante das questões vernáculas da língua realmente importantes para os candidatos. Esperase que um candidato a cargo público tenha um domínio do registro formal da língua para que possa se comunicar de maneira precisa e ausente de coloquialismos que poderiam prejudicar o entendimento das informações. É preciso salientar, também, que, na avaliação, o candidato deve mostrar habilidades cognitivas de resolução de problemas, muitas vezes de ordem semântica e/ou pragmática, a fim de medir sua capacidade de expressão linguística e de compreensão de informações explícitas ou implícitas por meio da leitura. Dois problemas se descortinam face a esse pressuposto de cobrança: o primeiro é relativo a que tipo de conhecimento estrutural pode ser cobrado de um indivíduo,

3 Tomamos a terminologia item para nos referir às questões de provas. 
falante de Língua Portuguesa, egresso do ensino médio ou do ensino superior; o segundo é referente ao tipo de texto que pode ser apresentado para o candidato, a fim de que extraia informações essenciais para a compreensão.

Não parece razoável exigir de um candidato que não tenha direcionamento específico de estudos em Língua Portuguesa saber identificar a função sintática de um pronome relativo em uma oração subordinada adjetiva; assim como não parece ser plausível exigir que faça inferências a respeito do conteúdo de um texto (adaptado) escrito por René Descartes em cerca de 35 ou 40 minutos. A falta de razoabilidade apontada se deve ao fato de que - a menos que o concurso seja para um cargo extremamente específico - dificilmente o candidato irá se deparar com uma situação comunicativa dessa natureza no exercício de sua função em autarquias, tribunais ou empresas mistas que realizam concurso para provimento de vagas. Portanto, o que se tem avaliado nos concursos atuais é a memorização de uma gama de conhecimentos específicos e conteúdos que sequer são ensinados com profundidade nas séries do Ensino Médio (e sequer passam pelas disciplinas do Ensino Superior, quiçá no curso de Letras).

${ }^{4}$ Banca: FGV (2016)

Órgão: COMPESA

4 Extraído da Fundação Getúlio Vargas. O levantamento se deve a Pablo Jamilk Flores. 
Prova: Assistente de Tecnologia da Informação

Leia a frase: "Sou como uma planta do deserto. Uma única gota de orvalho é suficiente para me alimentar".

Nesse pensamento há uma oração reduzida sublinhada; essa oração, se modificada para a forma de uma oração desenvolvida, deveria ser:

a) para que me alimentasse.

b) para que eu fosse alimentado.

c) para a minha alimentação.

d) para que eu me alimente. (gabarito)

e) para eu ser alimentado.

Nos materiais didáticos atuais, livros de Língua Portuguesa utilizados como fundamento para o Ensino Médio brasileiro, são raríssimos os casos de lições a respeito de como desenvolver uma oração reduzida e vice-versa (eram muito comuns esses exercícios nos livros didáticos do passado). Isso quer dizer que - para justificar a cobrança de uma questão dessa natureza - um candidato qualquer (mesmo que bem formado em seus estudos ginasiais) deveria ter plenas condições de operar esse tipo de procedimento gramatical; o que, com efeito, passa longe de ser a realidade do falante médio brasileiro. Se voltarmos o olhar para o cargo a que se destina o certame, chegaremos à conclusão de que, dificilmente ou nunca, um assistente de tecnologia da informação irá lidar, em seu cotidiano, com grandes 
transformações oracionais - a ponto de reconhecer aquilo que se nomeia como oração desenvolvida, bem como sua transformação para uma reduzida.

Banca: FGV (2008)

Órgão: Senado Federal

Prova: Técnico Legislativo - Administração

"Mas o fato é que transparência deixou

de ser um processo de observação

cristalina para assumir um discurso

de políticas de averiguação de custos

engessadas que pouco ou quase nada retratam as necessidades de populações distintas." (L.3-7)

A oração grifada no trecho acima classifica-se como:

a) subordinada substantiva predicativa. (gabarito)

b) subordinada adjetiva restritiva.

c) subordinada substantiva subjetiva.

d) subordinada substantiva objetiva direta.

e) subordinada adjetiva explicativa.

Esse é mais um exemplo de questão cujo conteúdo remonta as aulas de Língua Portuguesa do Ensino Médio do passado e que não mais é cobrado desse modo nos concursos vestibulares e no ENEM, por exemplo, que já concebem o domínio da língua de forma diferente e mais aplicável aos propósitos comunicativos de que se precisa para inserção no mercado de trabalho. Nada contra exigir o mínimo de conhecimento a respeito da norma culta - que poderia se 
traduzir, na questão mencionada, em uma investigação sobre o emprego da preposição "para" ou da conjunção "mas" em sua relação para a construção do sentido. Na realidade, é necessário que um técnico legislativo do Senado Federal seja capaz de lidar com as regras gramaticais na composição de sentenças. Saber que uma oração é subordinada substantiva predicativa não torna o período mais claro, tampouco o ofício do técnico mais preciso (a menos que se trate de um cargo específico de revisor textual, o que não é o caso). Com efeito, o propósito da questão é uma avaliação que objetiva os conhecimentos nomenclaturais que o candidato conseguiu adquirir durante sua preparação. Segue mais um exemplo do que se discute:

Banca: FGV (2017)

Órgão: ALERJ

Prova: Analista Legislativo

O vocábulo abaixo que é formado pelo processo de parassíntese é:

a) pré-história;

b) inconstitucional;

c) perigosíssimo;

d) embarque;

e) desalmado. (gabarito)

Nesse caso, espera-se que o candidato ao cargo de analista legislativo seja capaz de compreender os processos de formação de vocábulos em Língua Portuguesa, mais especificamente o caso da parassíntese. Talvez, dentre 
os exemplos arrolados, o supramencionado seja o mais complexo para se justificar como elemento de avaliação, uma vez que nem mencionado na NGB o conceito de

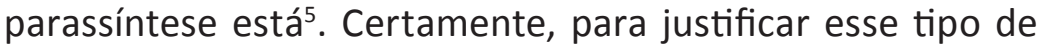
posicionamento, o elaborador da prova poderia argumentar que bastaria ao candidato (ou ao docente) ler o edital que contém os conteúdos programáticos, a fim de reconhecer os que farão parte da avaliação. Segue o edital do mesmo concurso, na seção que apresenta os conteúdos de Língua Portuguesa que ensejariam as questões:

Interpretação de textos argumentativos, com destaque para métodos de raciocínio e tipologia argumentativa; processos de construção textual; a progressão textual; as marcas de textualidade: a coesão, a coerência e a intertextualidade; reescritura de frases em busca da melhor expressão escrita; domínio vocabular e sua importância na construção do sentido do texto; a presença dos estrangeirismos em nosso léxico; os diversos usos das várias classes de palavras; a organização sintática e o emprego dos sinais de pontuação; a variação linguística e sua adequação às diversas situações comunicativas; a linguagem denotativa e a conotativa; a nova ortografia. (ASSEMBLEIA LEGISLATIVA DO RIO DE JANEIRO Edital no 2, de 06 de setembro de 2016)

5 Sobre esse assunto, ver Nascentes (1959). 
Muitos conteúdos estão indicados nesse edital; muitos extremamente relevantes para a prática comunicativa do futuro servidor público em seu labor. No entanto, por mais que se investiguem os itens apontados para a preparação dos pleiteantes a uma vaga, não se encontra o item "estrutura e formação de palavras". Isso quer dizer que, além das nomenclaturas presentes nos livros de gramática (tributários ou não da NGB), o candidato também deve reconhecer quais conteúdos podem ser cobrados em um certame, mesmo que não estejam expressos claramente nos editais. Talvez esse seja o cerne de algo que se costumou chamar, nos últimos anos, de "o entendimento da banca examinadora". Tal comportamento tem aparecido como justificativa para que estejamos sujeitos a diversas inconsistências nos exames, sem qualquer tipo de justificativa teórica - o que é pior do que simplesmente adotar uma nomenclatura tradicional ou sem respaldo na literatura canônica e confiável de gramática. Se conhecer a nomenclatura (diante de uma descontinuidade conceitual) já é pantanoso, ser capaz de captar as diferentes correntes teóricas - muitas vezes volúveis - das bancas examinadoras é uma missão inglória.

A cobrança de nomenclatura (conhecida ou inusitada) em todas essas situações relatadas é um óbice ao sucesso 
nos concursos e está em contraponto com as propostas pedagógicas que põem abaixo o ensino nomenclatural da língua, determinadas nos textos dos Parâmetros Curriculares Nacionais, o que nos parece uma incongruência das bancas examinadoras.

O ensino de Língua Portuguesa, pelo que se pode observar em suas práticas habituais, tende a tratar essa fala da e sobre a linguagem como se fosse um conteúdo em si, não como um meio para melhorar a qualidade. É o caso, por exemplo, da gramática que, ensinada de forma descontextualizada, tornou-se emblemática de um conteúdo estritamente escolar, do tipo que só serve para ir bem na prova e passar de ano - uma prática pedagógica que vai da metalíngua para a língua por meio de exemplificação, exercícios de reconhecimento e memorização de nomenclatura. Em função disso, tem-se discutido se há ou não necessidade de ensinar gramática. Mas essa é uma falsa questão: a questão verdadeira é para que e como ensiná-la. (p.31)

Como bem observado na citação do PCN de Língua Portuguesa, urge que se tenha mais zelo e afinidade contextual no que se exige dos candidatos hodiernos, visto serem bem diferentes dos de antanho. Houve toda uma revolução moderna na tecnologia, nos relacionamentos interpessoais, no mundo como um todo, entretanto a 
informação transmitida e cobrada por muitos certames ainda é antiquada e desconexa da realidade.

Em nossa visão, há um desvio de foco por parte dos professores responsáveis pela elaboração das provas dos certames. Existe uma grande diferença entre gramática didática e gramática científica. Alguns autores entendem essa distância e criticam a falta de harmonia entre escola (onde se deve operar com uma gramática didática) e universidade (seleiro adequado à produção de pesquisas que compõem as gramáticas científicas). É o que nos afirma NEVES:

A pesquisa acadêmica tem sido dividida em pura e aplicada. Uma e outra têm-se sustentado, em geral, independentemente de uma interação efetiva com o ensino fundamental e médio. [...] Não culpo os pesquisadores, mas verifico que o caráter em geral episódico das avaliações faz que o esforço não se organize em parcelas que possam somar-se, criando um corpo significativo de contribuição. (2002, p.230)

Falemos, agora, das salas de aula de cursos preparatórios. O que significam, para os professores desse segmento, as pesquisas que a universidade faz? Neves (2002) as entende, para a educação básica, como fonte de intimidação. Cita teorias como "ruptura de adjacências" do gerativismo e "iconicidade" do funcionalismo, a fim de ilustrar sua tese. Algumas dessas teorias são defendidas pelos mesmos 
professores que elaboram as provas de concursos. E mais: ainda temos de nos conformar com livros didáticos sendo usados como se fossem gramáticas, para fins de elaboração de itens ou mesmo para consulta de discentes e docentes, como forma de estudo ou de preparação de aulas.

\section{A NOMENCLATURA}

É necessário aprender Português. Se, ao menos, soubesse para quê? (E. Benveniste, 1966)

Partimos do trecho em epígrafe, extraído dos escritos de Benveniste, para motivar o capítulo e iniciar a hipótese de que o domínio linguístico é elemento de promoção social. Em especial no segmento do concurso público, essa hipótese se confirma como tese, já que saber os recursos linguísticos e os fatos da língua (domínio gramatical) podem ser determinantes para a aprovação nos certames que garantem o ingresso no tão sonhado e bem remunerado serviço público. E embora tenhamos nos posicionado contrários ao ensino puramente nomenclatural e memorizador, entendemos que nomear os fatos vinculados à língua "funciona como elemento simplificador e unificador", nas palavras de Domício Proença Filho (HENRIQUES, 2009, p.9). Citamos trecho da apresentação do livro de Henriques, onde Domício diz 
[...] durante muito tempo, os especialistas divergiam, por vezes radicalmente. Os professores dividiam-se entre a confusão e a perplexidade. Os estudantes perdiamse no emaranhado de classificações, designações, conceitos.

Emergente em 1959, a Nomenclatura Gramatical Brasileira trouxe alguma organização ao caos então vigente. Alguma, porque conviveu com a divergência, mesmo de integrantes do próprio grupo de renomados especialistas que participaram de sua elaboração.

Tais dissenções - associadas ao progresso de estudos da língua, ao notável desenvolvimento dos estudos linguísticos, à caducidade de alguns conceitos, a persistentes imprecisões terminológicas, às mudanças de perspectivas - evidenciaram, ao longo do tempo, a necessidade de repensar uma possível reformulação daquele documento padronizador.

É flagrante a necessidade de reformular a Nomenclatura Gramatical Brasileira (NGB), por motivos já elucidados por Domício. Mas não podemos esquecer que, no segmento de concursos, é necessário que se opte ou por uma nomenclatura registrada ou por uma bibliografia em que se possam apoiar os estudos sem, no entanto, privilegiar o interesse de grupos de escritores que se beneficiariam com a venda de livros. Essa simples ação facilitaria o trabalho dos docentes que se 
dedicam a esse segmento.

Nas palavras de Baldini, podemos nos apoiar

[...] a nomenclatura também se insere em outro recorte que o autor propõe, que é o de trabalhos sem filiação teórica definida. Assim, a NGB, além de ser uma tentativa de valorização do que é específico no Brasil, não se filia rigorosamente a nenhuma teoria. [...]Nesse sentido, podemos dizer que, a partir da NGB, um outro momento de autoria se estabelece no discurso gramatical. Nesse outro momento, o gramático não é mais a autoridade do saber sobre a língua, mas um comentador desse saber. E esse é um deslocamento proporcionado pela NGB. (2000, p.3-6)

Para exemplificar a dissenção flagrante de nomenclatura, trouxemos um exemplo, retirado de uma questão da Fundação Getúlio Vargas (FGV). Desde 2013, a banca FGV começou a "inovar" em suas provas. Dentre essas novidades, podemos apontar uma terminologia chamada "adjetivo de relação", nomenclatura encontrada em duas gramáticas de autores consagrados: Celso Cunha \& Lindley Cintra e José C. Azeredo.

Vejamos a questão:

FGV - SMF (PREF. NITERÓI/RJ) CONTADOR - 2015

- Há uma série de adjetivos em Língua Portuguesa, chamados adjetivos de 
relação, que se caracterizam, entre outras marcas, por não poderem receber variação de grau. $\mathrm{O}$ adjetivo abaixo que está nesse caso é:

(A)

(D)

(E) baixas taxas. economia

longo

expansão

nova mundial; ciclo; acelerada; paisagem;

Por definição, segundo PESTANA (2013, p.219), adjetivo de relação é aquele que tem valor semântico objetivo (não expressa ponto de vista); é derivado por sufixação de um substantivo; posiciona-se após o substantivo; não possui grau superlativo, ou seja, não pode ser intensificado. Exemplos: vinho português, energia nuclear, baile carnavalesco.

Voltemos à questão da banca. O gabarito é a letra $A$, pois o adjetivo "mundial" preenche todos os requisitos dum adjetivo de relação, a saber: tem valor semântico objetivo (mundial = relativo ao mundo), não varia em grau (não cabe "muito mundial" ou "mundialíssimo") e é derivado por sufixação de um substantivo (mundo < mundial).

Como vemos, saber gramática e conhecer todas as nomenclaturas antigas ou contemporâneas não é o caminho para se adquirir competência em português padrão. Não pretendemos aqui discutir esse fato, que já foi amplamente abordado por linguistas e gramáticos consagrados, como 
Maria Helena de Moura Neves, Sírio Possenti, Darcilia Simões, Gladstone Chaves de Melo, Claudio Cezar Henriques, José Carlos de Azeredo e outros tantos. Conhecer todas as regras de gramática não é condição para usar com alguma competência a língua padrão, tampouco saber as regras implica bom domínio verbal.

Consultando o livro escrito por Cláudio Cezar Henriques em Nomenclatura Gramatical Brasileira: 50 anos depois e lendo algumas das contribuições de diversos gramáticos e linguistas na obra, vemos uma preocupação constante, qual seja a de que se deve tomar cuidado com certas questões em concursos, já que a nomenclatura está ultrapassada e carece de atualização, segundo novos estudos e pesquisas. Sírio Possenti, conceituado linguista, afirma não servir para nada a NGB da maneira como se encontra ultrapassada e alerta: "Claro que, então, não deveria haver certas questões em provas escolares ou concursos" (HENRIQUES, 2009, p.119). No mesmo livro, Maria Helena de Moura Neves afirma:

Considero necessária a existência de uma nomenclatura gramatical uniforme para efeito de padronização em concursos e exames classificatórios que exijam formação nos níveis de ensino fundamental e médio, por exemplo, em exames vestibulares. (HENRIQUES, 2009, p.105) 
Terminamos esta seção com as palavras experientes de Darcilia Simões:

Primeiramente é preciso que o docente esteja cônscio das ações que terá de re alizar para preparar os discentes para a competência linguística exigida pelas práticas sociais.

O docente deve orientar os alunos a organizar a fala segundo suas instâncias pública e privada; ensinar-lhes a modalidade escrita; demonstrar a variação linguística, a importância do uso padrão, as várias possibilidades de estilo, o uso do jargão, os usos artísticos literário e publicitário, além de identificar semelhanças e diferenças entre os usos. (SIMÕES, 2008, p.187)

\section{À GUISA DE CONCLUSÃO}

A despeito de a conclusão desses motes estar bem distante (pois apenas iniciamos o trabalho neste texto), é forçoso apresentar um resultado para o que discutimos anteriormente. É inconteste o fato de que a seara relativa à produção de questões para exames em concursos públicos é imensa e carece de sistematização e uniformização teórica. Essa situação acaba por criar um problema de descontinuidade conceitual, o qual transparece a arbitrariedade na adoção de perspectivas teóricas para avaliar aquilo que é julgado "de conhecimento geral".

O paradoxo apontado não é privilégio das provas de Língua Portuguesa, mas nosso propósito é denunciar como 
esse fenômeno grassa a cada certame aplicado no Brasil. Entendemos que a oposição entre aquilo que deveria compor o conteúdo programático dos editais de concursos púbicos e aquilo que se nota nos itens das provas é o cerne de um processo muito mais grave. Este revela o apagamento dos estudos relativos ao ensino da língua como forma de preparar os discentes para uma competência linguística e, concomitante, o surgimento de modelos analíticos diversos, num contexto em que muitos estudiosos, servindose de teorias modernas, vão utilizando nomenclaturas desconhecidas do público desses concursos. Como podem docentes e discentes dar conta de tudo isso para um único propósito: uma prova?

Queremos ressaltar que essa arbitrariedade saliente (e que se multiplica em progressão geométrica) coloca em xeque o preparo dos profissionais que debruçam sobre a preparação de seus alunos para esses exames. Ao aluno que não possui formação específica na área - cabe atribuir juízos a respeito daquilo que encontra nas provas que tenta resolver. Caso obtenha êxito - porque ouviu os nomes e termos coincidentes durante as aulas nos preparatórios -, terá a certeza de que o profissional com quem estudou está bem preparado; caso contrário, pensará que o professor de "cursinho" nada sabe, pois apenas decorou algumas 
fórmulas e algumas dicas. Mal sabe o candidato que, como se viu por meio dos exemplos apresentados, o professor além de investir em sua capacitação profissional - ainda se coloca em uma "loteria" de conceitos, na qual espera ser "premiado" com o bom resultado de seus discípulos, o que garante, pelo menos nessa ocasião, seu emprego nos cursos preparatórios.

O problema está configurado, é evidente e constante. Cabe aos próximos trabalhos a descrição pormenorizada dos fenômenos e a indicação de um caminho senão para sua resolução, ao menos para sua disseminação em outras esferas.

\section{REFERÊNCIAS}

ASSEMBLEIA LEGISLATIVA DO RIO DE JANEIRO Edital no 2, de 06 de setembro de 2016 in http://netstorage.fgv.br/alerj2016/Edital_ Concurso_ALERJ_NS_17_10_2016_Retificado_prorrogacao.pdf Acesso em 18.Jul.2017

BALDINI, Lauro (2000). "A Nomenclatura Gramatical Brasileira Interpretada, definida, comentada e exemplificada". In: Sínteses (5), 5981. Campinas - SP: IEL - UNICAMP.

BENVENISTE, Émile (1966). Problèmes de Linguistque Générale. 1. Paris: Gallimard.

HENRIQUES, Claudio Cezar (2009). Nomenclatura gramatical brasileira: 50 anos depois. São Paulo: Parábola Editorial.

HENRIQUES, Claudio Cezar; SIMÕES, Darcilia (Orgs.) (2008). Língua portuguesa, educação e mudança. Rio de Janeiro: Editora Europa.

NASCENTES, Antenor (1959). Comentário à Nomenclatura Gramatical 
Brasileira. Rio de Janeiro: Acadêmica.

NEVES, Maria Helena de Moura (2002). A gramática: história, teoria e análise, ensino. São Paulo: Editora UNESP.

PESTANA, Fernando (2013). A Gramática para concursos públicos. Rio de Janeito: Editora Campus.

SECRETARIA DE EDUCAÇÃO FUNDAMENTAL. Parâmetros curriculares nacionais: língua portuguesa / Secretaria de Educação Fundamental. Brasília: 144p. 1.Parâmetros curriculares nacionais. 2. Língua portuguesa: Ensino de primeira à quarta série. I. Título.

SIMÕES, Darcilia (2008). "Se persistirem os sintomas, procure a gramática". In: HENRIQUES, Claudio Cesar; SIMÕES, Darcilia (Orgs.). Língua Portuguesa, Educação e Mudança. Rio de Janeiro: Editora Europa.

Rosane Reis de Oliveira é Doutora em Letras pela UERJ (2010). Dedicase a estudar a gramática da língua portuguesa sob perspectiva semiótica e metodologia do ensino de redação. Autora do livro Redação em Concursos, com Maria Emília Barcellos, Editora Ferreira. É membro do grupo de pesquisa SELEPROT/CNPq (Semiótica, Leitura e Produção textual) e da ALFAL (Associação de Linguística e Filologia da América Latina). URL: www.rosanereis.com.br. E-mail: rosanereis.redacao@gmail.com

Pablo Jamilk Flores é doutorando em Letras pela UNIOESTE. Dedicase ao estudo da língua portuguesa com base nos fundamentos da semântica e da pragmática. É autor do livro Interpretação de Textos (Série Revisaço), Editora JusPodivm. URL: www.pablojamilk.com.br. E-mail: pablojamilkflores@hotmail.com

Denis Rogério Romagnoli é pós-graduado em Didática do Ensino Superior (2015) e graduado em Letras pela UFPel (2004). Dedica-se à docência da Língua Portuguesa desde 2002 e leciona somente para concursos públicos desde 2010. E-mail: profedenis@gmail.com 